\title{
OPTIMALISASI KOMBINASI BUDIDAYA IKAN LELE (Clarias $s p$ ) DAN PATIN (Pangasius pangasius) DI DESA KURO TIDUR KECAMATAN ARGAMAKMUR KABUPATEN BENGKULU UTARA
}

\author{
Optimization Combination Cultivation Of Catfish (Clarias sp) AND \\ Patin Fish (Pangasius pangasius) In The Kuro Tidur Village Subdistrict \\ Argamakmur North Bengkulu Regency. \\ Avif Mujiarto, Nusril, dan Gita Mulyasari \\ Jurusan Sosial Ekonomi Pertanian Fakultas Pertanian Universitas Bengkulu
}

\begin{abstract}
Research titled optimization combination cultivation of fish catfish (Clarias sp) and patin (Pangasius pangasius) in the Kuro Tidur Village Subdistrict Argamakmur North Bengkulu Regency, aims to understand the large income levels and combination cultivation of catfish and patin fish in the pool belonging to Mr. Azmi Nur in the Kuro Tidur Village subdistrict Argamakmur North Bengkulu Regency condition steady and profit maximum. The determination of location and respondents in this research is deliberately (purposive) that is a unit of the business of cultivating fishes belonging to Mr. Azmi Nur located in the Kuro Tidur Village Subdistrict Argamakmur North Bengkulu Regency, with the business owners produces product more than one, which is kinds of fish catfish and patin fish. Instrument the analysis used is income analysis and linear programming analysis to know the optimal fish combination and give benefits maximum. After analyzed the results of operating income cultivation of fish belonging to Mr. Azmi Nur in 10 months production activities is $R p$ 1.061.610.350,02. With contribution of income from production of fish catfish $R p$ 528.553.700,00 and patin fish $\mathrm{Rp} 533.056 .650,02$. And a combination of optimal within 10 months production to cultivation of catfish is 15220,29 square meters and not cultivate patin fish, contributing margin maximum $R p$ 1.527.393.000,-. Resources overgrowth is broad pond 779,7139 square meters and 9075,394 working hours labor. As for resources any excess can economy is broad the pool of 779,7139 square meters and working hours jobs for 9075,394 hours.
\end{abstract}

Key Words : Catfish, Patin fish, Optimization

\section{PENDAHULUAN}

\section{Latar Belakang}

Sebagai salah satu subsektor pertanian, perikanan memiliki peranan yang cukup penting, terutama dikaitkan dengan upaya meningkatkan kualitas dan kuantitas produksi perikanan yang diarahkan untuk meningkatkan pendapatan 
dan taraf hidup masyarakat, menghasilkan protein hewani dalam rangka memenuhi kebutuhan pangan dan gizi, meningkatkan ekspor, menyediakan bahan baku industri, memperluas lapangan kerja dan kesempatan berusaha, serta mendukung pembangunan wilayah dengan tetap memperhatikan kelestarian dan fungsi lingkungan hidup (Parwinia 2001 dalam Suhardedi 2010).

Hasil Sensus Pertanian Bengkulu (2013) menunjukan usaha budidaya ikan air tawar di Provinsi Bengkulu, paling banyak rumah tangga mengusahakan ikan di kolam dan di sawah. Tercatat sebanyak 6.725 rumah tangga di Provinsi Bengkulu mengusahakan budidaya ikan di kolam, sedangkan sebanyak 3.382 rumah tangga mengusahakan budidaya ikan di sawah. Kabupaten Bengkulu Utara merupakan kabupaten yang memiliki rumah tangga terbanyak yang mengusahakan budidaya ikan di kolam, yaitu sebanyak 1.804 rumah tangga.

Setiap usaha yang didirikan baik skala besar maupun kecil dan apapun jenis usahanya dalam hal ini usaha dibidang perikanan darat, didirikan mempunyai suatu tujuan yang ingin dicapai. Secara umum, tujuan perusahaan akan selalu berpijak pada prinsip ekonomi yaitu dengan biaya yang sedikit dapat memperoleh keuntungan yang sebesar-besarnya. Dengan demikian agar tercapai tujuan tersebut tidak jarang perusahaan memproduksi lebih dari satu jenis produk agar memberikan kontribusi keuntungan yang berbeda-beda yang selanjutnya dapat ditentukan atau dikombinasikan berapa masing-masing produk harus diproduksi untuk dapat memperoleh laba yang maksimal. Untuk mewujudkan tujuan tersebut, suatu perusahaan seringkali dihadapkan pada persoalan-persoalan yang rumit, dimana keputusan yang tepat harus diambil. Adanya pembatasan-pembatasan di dalam lingkungan operasi juga merupakan tantangan bagi perusahaan untuk mencapai tujuan di dalam perusahaan tersebut. Pembatasan-pembatasan tersebut meliputi terbatasnya sumber daya, waktu, tenaga, energi, bahan baku, uang dan lain-lain.

Demikian halnya usaha budidaya ikan air tawar milik Pak Azmi Nur yang terdapat di Desa Kuro Tidur Kecamatan Argamakmur Kabupaten Bengkulu Utara. Pak Azmi Nur seorang pengusaha sukses yang telah melalang buana dibidang perikanan. Pak Azmi Nur memiliki banyak sentra usaha perikanan di beberapa tempat seperti di Kelurahan Padang Serai Kota Bengkulu dan di Desa Kuro Tidur itu sendiri. Pak Azmi Nur bergelut dalam budidaya ikan air tawar di desa Kuro Tidur ini kurang lebih sejak 10 tahun silam. Dahulu di luas kolam keseluruhan \pm 1,6 hektar ini banyak jenis ikan yang dikembangbiakan, namun sekarang hanya ada dua kombinasi jenis ikan yang dibudidayakan yaitu ikan lele dan ikan patin.

Adanya aliran air sungai Lais yang melimpah tentu menjadi salah satu pendukung keberlangsungan proses budidaya ikan air tawar yang tidak kenal akan masalah kekeringan air. Meskipun demikian masih ada faktor-faktor lain yang dapat menghambat tujuan Pak Azmi Nur untuk meningkatkan usahanya agar memperoleh laba semaksimal mungkin, seperti luas lahan, tenaga kerja, 
waktu, dsb. Dan hal tersebut menjadi tantangan tersendiri yang harus dipecahkan seseorang pengusaha agar tujuannya tercapai.

Dengan latar belakang demikian saya merasa tertarik untuk melakukan penelitian untuk Mengetahui besar tingkat pendapatan usaha dan Mengetahui besaran kombinasi budidaya ikan lele dan patin di kolam milik Pak Azmi Nur di Desa Kuro Tidur Kecamatan Argamakmur Kabupaten Bengkulu Utara dalam kondisi optimum dan keuntungan maksimum.

\section{METODOLOGI PENELITIAN}

Penelitian ini dilakukan pada usaha budidaya ikan lele dan patin milik Pak Azmi Nur di Desa Kuro Tidur Kecamatan Argamakmur Kabupaten Bengkulu Utara. Penentuan lokasi dan responden dilakukan secara sengaja (purposive) dengan pertimbangan usaha tersebut menghasilkan produk lebih dari satu, yaitu ikan lele dan ikan patin dan skala usaha lebih dari 1 Ha. Data yang digunakan dalam penelitian ini berupa data primer dan data sekunder, untuk mengali data yang dibutuhkan untuk penelitian dilakukan selama 7 hari.

Selanjutnya untuk menganalisis dari tujuan penelitian yang pertama yaitu mengetahui tingkat pendapatan usaha budidaya ikan selam 10 bulan menerapkan analisis pendapatan metode variable costing dan full costing. Dan untuk tujuan penelitian kedua yaitu menentukan kombinasi optimal ikan lele dan patin yang memberikan keutungan kontribusi marjin yang maksimal menggunakan Alat analisis Linier Programming (aplikasi POM For Windows versi 3.0) yaitu dengan membuat nilai suatu fungsi beberapa variabel menjadi maksimal.

Adapun perumusan fungsi tujuan dan fungsi kendala dalam penelitian yang dilakukan dalam batasan waktu 10 adalah sebagai berikut :Fungsi Tujuan $Z-C_{1} X_{1}-C_{2} X_{2}-0 S_{1}-0 S_{2}-0 S_{3}=0$

dimana, $\mathrm{Z}$ adalah Kontribusi marjin total ikan lele dan ikan patin, $\mathrm{C}_{1}$ adalah Kontribusi marjin ikan Lele ( $\left.\mathrm{Rp} / \mathrm{m}^{2}\right), \mathrm{C}_{2}$ adalah Kontribusi marjin ikan Patin $\left(\mathrm{Rp} / \mathrm{m}^{2}\right), \mathrm{X}_{1}$ adalah Budidaya Ikan Lele pada luas kolam per $\mathrm{m}^{2}, \mathrm{X}_{2}$ adalah Budidaya Ikan Patin pada luas kolam per $\mathrm{m}^{2}$

\section{Fungsi Batasan/Kendala}

$$
\begin{aligned}
\text { i. } & a_{11} X_{1}+a_{12} X_{2}+S_{1}+0 S_{2}+0 S_{3}=b_{1} \\
\text { ii. } & a_{21} X_{1}+a_{22} X_{2}+0 S_{1}+S_{2}+0 S_{3}=b_{2} \\
\text { iii. } & a_{31} X_{1}+a_{32} X_{2}+0 S_{1}+0 S_{2}+S_{3}=b_{3}
\end{aligned}
$$

\section{Batasan non negatif:}

$$
\mathrm{X}_{1}, \mathrm{X}_{2} \geq 0
$$


dimana, $a_{i j}$ adalah Koefisien teknis, i adalah 1 (Luas kolam adalah $\mathrm{m}^{2} /$ Produksi), 2 (Jam kerja tenaga kerja adalah Jam / $\mathrm{m}^{2}$ ), 3 (Harga pokok produksi variabel adalah Rp / m²/ Produksi), $X_{j}$ adalah Tingkat kegiatan ke j (Budidaya Ikan), j adalah 1 (Budidaya Ikan Lele), 2 (Budidaya Ikan Patin), bi adalah Banyaknya sumberdaya yang tersedia untuk dialokas ikan dalam proses budidaya ikan Lele dan ikan Patin, $b_{1}$ adalah Total Luas kolam ( $\mathrm{m}^{2} /$ Produksi), $b_{2}$ adalah Jumlah jam kerja tenaga kerja yang tersedia dalam 10 Bulan (Jam), $b_{3}$ adalah Jumlah modal kerja yang tersedia (Rp/ Produksi), dan S adalah Slack yang merupakan variabel yang menyatakan kapasitas yang tidak digunakan atau tersisa pada sumber daya.

\section{HASIL DAN PEMBAHASAN}

\section{Karakteristik Responden}

Dari hasil penelitian diketahui karakteristik pemilik usaha nama pengusaha pak Azmi Rais dan lebih dikenal akrab pak Azmi Nur. Umur 45 tahun, dengan umur berada pada kisaran 15-64 tahun maka pak Azmi tergolong usia produktif. Usia produktif akan memberikan hasil kinerja yang maksimal jika dibandingkan umur di bawah ataupun di atas umur produktif. Pendidikan formal pak Azmi Sekolah Menengah Atas (SMA), pendidikan SMA termasuk pendidikan yang cukup tinggi, dimana pada pendidikan setingkat SMA telah dapat memahami manajemen organisasi dan pengaturan akan keuangan, ditambah dengan pendidikan informal mengenai budidaya ikan dari pak Afrizal yang merupakan rekan bisnisnya menambah wawasan pengetahuan pak Azmi mengenai bisnis dibidang perikanan.

Berbekalkan pendidikan formal dan informal, pak Azmi yang memiliki pekerjaan swasta tidak menutup kemungkinan untuk pak Azmi terus mengembangkan usahanya. Dengan pengalaman usaha budidaya ikan yang telah ditekuninya selama kurang lebih 10 tahun, pak Azmi dapat mensejahtrakan kelima anggota keluarganya yang bertempat tinggal di Jalan Mahakam 5 Lingkar Barat Kota Bengkulu.

\section{Pendapatan Usaha}

Penghitungan pendapatan ini merupakan tujuan pertama dan sebagai data acuan untuk tujuan kedua dalam penelitian ini. Dimana untuk mengetahui pendapatan dapat dilakukan dengan mengurangkan penerimaan yang diperoleh dari masing-masing produksi jenis ikan dengan masing-masing biaya yang dikeluarkan saat budidaya ikan tersebut. Adapun rincian pengunaan biaya, produksi dan penerimaan akan dijelaskan pada pembahasan berikut. 


\section{Biaya Usaha}

Biaya adalah sejumlah nilai korbanan yang dikeluarkan untuk menghasilkan suatu produk, biaya ini ada dua macam yaitu biaya variabel dan biaya tetap. Biaya variabel adalah biaya yang jumlahnya berubah-ubah seiring dengan jumlah produksi, sedangkan biaya tetap adalah biaya yang jumlahnya tetap meskipun jumlah produksinya berubah.

\section{Biaya Tetap}

Biaya tetap yang dikeluarkan pada usaha budidaya ikan dapat dilihat pada rincian tabel berikut:

\section{Tabel 1. Rincian Total Biaya Tetap}

\begin{tabular}{|c|c|c|c|c|c|}
\hline \multirow[b]{2}{*}{ No } & \multirow[b]{2}{*}{$\begin{array}{c}\text { Rincian Biaya } \\
\text { Tetap }\end{array}$} & \multicolumn{2}{|c|}{ Ikan Lele } & \multicolumn{2}{|c|}{ Ikan Patin } \\
\hline & & Nilai (Rp) & $\begin{array}{c}\text { Persentase } \\
(\%)\end{array}$ & Nilai (Rp) & $\begin{array}{c}\text { Persentase } \\
(\%)\end{array}$ \\
\hline 1 & Gaji Tenaga Kerja & $66.000 .000,00$ & 89,72 & $107.000 .000,00$ & 90,42 \\
\hline 2 & Penyusutan Alat & 7.299.166,68 & 9,92 & $10.948 .750,00$ & 9,25 \\
\hline 3 & Pajak PBB & $19.333,32$ & 0,03 & $28.999,98$ & 0,03 \\
\hline 4 & Beban Listrik & $240.000,00$ & 0,33 & $360.000,00$ & 0,30 \\
\hline & Total Biaya & $73.558 .500,00$ & 100 & $118.337 .749,98$ & 100,00 \\
\hline & Biaya $\left(\mathrm{m}^{2}\right)$ & $12.259,75$ & & $11.833,77$ & \\
\hline
\end{tabular}

Sumber : Olahan data primer tahun 2015

Dari tabel di atas diketahui secara keseluruhan rincian biaya tetap yang terjadi dengan total biaya tetap ikan patin Rp 118.337.749,98 lebih besar daripada ikan lele Rp 73.558.500,00. Pengeluaran biaya tetap terbesar adalah untuk biaya gaji tenaga kerja yang mendekati $90 \%$, baik untuk budidaya ikan lele maupun patin. Biaya tetap untuk ikan patin yang lebih besar ini dikarenakan penghitungan proporsi biaya berdasarkan lama proses budidaya, dan lama budidaya per produksi untuk ikan patin lebih lama. Meskipun frekuensi produksi ikan patin lebih sedikit pengaruh tersebut tidak signifikan terhadap biaya tetap. Selain itu selisih gaji tenaga kerja lebih besar untuk ikan patin karena penggunaan tenaga kerja untuk budidaya ikan patin itu sendiri lebih banayak.

Total biaya tetap lebih besar untuk ikan patin tetapi untuk biaya per $\mathrm{m}^{2}$ lebih besar ikan lele dengan selisih keduanya yang relatif kecil $\operatorname{Rp} 425,98 / \mathrm{m}^{2}$. Ini dikarenakan faktor pembagi biaya tersebut yaitu luasan kolam untuk masing-masing jenis ikan lebih luas ikan patin $10000 \mathrm{~m}^{2}$ dan untuk ikan lele 6000 $\mathrm{m}^{2}$.

\section{Biaya Variabel}

Biaya variabel dalam budidaya ikan terdiri dari biaya input utama berupa bibit ikan, biaya tenaga kerja langsung dan biaya overhead variabel. 
Adapun biaya-biaya yang dikeluarkan selama proses budidaya ikan akan dirincikan pada Tabel 2.

\section{Tabel 2. Rincian Total Biaya Variabel}

\begin{tabular}{|c|c|c|c|c|c|}
\hline \multirow[b]{2}{*}{ No } & \multirow[b]{2}{*}{ Rincian Biaya Variabel } & \multicolumn{2}{|c|}{ Ikan Lele } & \multicolumn{2}{|c|}{ Ikan Patin } \\
\hline & & Nilai (Rp) & $\begin{array}{l}\text { Persenta } \\
\text { se }(\%)\end{array}$ & Nilai (Rp) & $\begin{array}{c}\text { Persentas } \\
\text { e }(\%)\end{array}$ \\
\hline 1 & Bibit Ikan & 360.000 .000 & 9,79 & 250.000 .000 & 6,64 \\
\hline \multirow[t]{4}{*}{2} & Input Penunjang & & & & \\
\hline & - Pupuk & 1.350 .000 & 0,04 & 1.500 .000 & 0,04 \\
\hline & - Obat-Obatan & 2.700 .000 & 0,07 & 5.400 .000 & 0,14 \\
\hline & - Pakan & 3.294 .523 .800 & 89,62 & 3.485 .816 .600 & 92,55 \\
\hline 3 & Upah Tenaga Kerja & 16.830 .000 & 0,46 & 22.440 .000 & 0,60 \\
\hline \multirow[t]{5}{*}{4} & Biaya Overhead & & & & \\
\hline & $\begin{array}{l}\text { - Operasional (Bahan } \\
\text { Bakar) }\end{array}$ & 264.000 & 0,01 & 259.000 & 0,01 \\
\hline & - Penggunaan Listrik & 460.000 & 0,01 & 690.000 & 0,02 \\
\hline & Total Biaya & 3.676 .127 .800 & 100,00 & 3.766 .105 .600 & 100,00 \\
\hline & Biaya $\left(\mathrm{m}^{2}\right)$ & 612.688 & & 376.611 & \\
\hline
\end{tabular}

Sumber: Olahan data primer tahun 2015

Dari Tabel 2 diketahui total biaya variabel selama 10 bulan budidaya ikan atau 3 kali produksi ikan lele dan 2 kali ikan patin pada kolam pak Azmi, dimana untuk budidaya ikan lele sebesar Rp 3.676.127.800,- dan untuk ikan patin Rp 3.766.105.600 dengan total keseluruhan Rp 7.442.233.400,-. Total biaya untuk ikan patin lebih besar dari pada ikan lele, selisih tersebut terjadi dipengaruhi biaya overhead untuk ikan patin yang begitu besar. Biaya overhead terbesar dikeluarkan untuk pembelian pakan, dengan umur panen yang lebih lama ikan patin membutuhkan jumlah pakan lebih banyak dari pada lele meskipun frekuensi produksinya lebih banyak lele. Namun meski total biaya variabel lebih besar ikan patin, tetapi untuk biaya per $\mathrm{m}^{2}$ lebih besar lele yaitu $\mathrm{Rp} 612.688$,- dan patin $\mathrm{Rp} 376.611,-$. Hal ini terjadi karena faktor pembagi yaitu luas lahan kolam ikan itu sendiri untuk ikan patin lebih luas $10000 \mathrm{~m}^{2}$ dan kolam ikan lele 6000 $\mathrm{m}^{2}$.

\section{Produksi dan Penerimaan Usaha}

Hasil produksi dan penerimaan budidaya ikan pada kolam pak Azmi ini dapat dilihat pada tabel berikut: 
Tabel 3. Produksi dan Penerimaan Usaha Budidaya Ikan

\begin{tabular}{clcccr}
\hline \multirow{2}{*}{ No } & \multicolumn{2}{c}{ Rincian } & \multirow{2}{*}{ Satuan } & \multicolumn{2}{c}{ Jenis Ikan } \\
\cline { 4 - 5 } & & & $\mathrm{Kg}$ & 267390 & Patin \\
\hline 1 & Total Produksi & (A) & $\mathrm{Rp} / \mathrm{Kg}$ & 16.000 & 294500 \\
2 & Harga & (B) & $\mathrm{Rp}$ & 15.000 \\
3 & Penerimaan & $(\mathrm{A} \times \mathrm{B})$ & $\mathrm{Rp}$ & 4.278 .240 .000 & 4.417 .500 .000 \\
\hline
\end{tabular}

Sumber : Olahan data primer tahun 2015

Berdasarkan tabel diketahui produksi total dalam 10 bulan untuk ikan lele dengan frekuensi produksi tiga kali adalah $267390 \mathrm{Kg}$ sedangkan ikan patin dengan frekuensi produksi 2 kali adalah $294500 \mathrm{Kg}$. Dengan harga ikan per kilogram untuk ikan lele Rp 16.000 diperoleh penerimaan sebesar Rp 4.278.240.000,- dan untuk ikan patin dengan harga per kilogramnya adalah $\mathrm{Rp}$ 15.000,- penerimaan yang diperoleh $\mathrm{Rp}$ 4.417.500.000,-. Total keseluruhan penerimaan usaha budidaya ikan milik pak Azmi dalam 10 bulan produksi adalah Rp 8.695.740.000,-.

Penerimaan untuk ikan patin lebih besar dibandingkan ikan lele meskipun harga ikan patin per kilogramnnya lebih murah. Hal tersebut terjadi karena meskipun frekuensi produksi lele lebih banyak yaitu 3 kali sedangkan patin 2 kali dalam 10 bulan, namun produksi ikan patin dalam sekali produksi hasilnya cukup tinggi dibandingkan lele.

\section{Pendapatan Usaha}

Suatu perusahaan dikatakan memperoleh pendapatan laba apabila penerimaan total lebih dari pengeluaran (biaya) total $(\mathrm{R}>\mathrm{C})$,dimana $\mathrm{R}$ adalah penerimaan dan C adalah biaya total (Dumairy 1999 dalam Laila 2007).

Pada pembahasan sebelumnya telah diuraikan mengenai biaya-biaya yang dikeluarkan dan penerimaan dari kegiatan budidaya ikan selama 10 bulan. Adapun rincian nilai tersebut tersaji pada tabel berikut :

Tabel 4. Pendapatan Usaha

\begin{tabular}{|c|c|c|c|c|}
\hline \multirow{2}{*}{ No } & \multirow{2}{*}{ Keterangan } & \multicolumn{2}{|c|}{ Jenis Ikan (Rp) } & \multirow{2}{*}{ Total (Rp) } \\
\hline & & Lele & Patin & \\
\hline 1 & Penerimaan (A) & $4.278 .240 .000,00$ & $4.417 .500 .000,00$ & $8.695 .740 .000,00$ \\
\hline 2 & Biaya Variabel (B) & 3.676.127.800,00 & 3.766.105.600,00 & 7.442.233.400,00 \\
\hline 3 & Kontribusi Margin $(\mathrm{C}=\mathrm{A}-\mathrm{B})$ & 602.112.200,00 & $651.394 .400,00$ & $1.253 .506 .600,00$ \\
\hline 4 & Biaya Tetap (D) & $73.558 .500,00$ & 118.337.749,98 & 191.896.249,98 \\
\hline 5 & Pendapatan (C-D) & $528.553 .700,00$ & $533.056 .650,02$ & $1.061 .610 .350,02$ \\
\hline
\end{tabular}

Sumber : Olahan data primer tahun 2015

Dari tabel di atas dapat dilihat baik nilai penerimaan dan rincian biaya dalam 10 bulan kegiatan budidaya ikan. Dan hasil perhitungan diketahui pendapatan total ikan lele $\mathrm{Rp} 528.553 .700,00$ dan untuk ikan patin $\mathrm{Rp}$ 
533.056.650,02, dengan jumlah pendapatan usaha budidaya kedua jenis ikan tersebut adalah $\mathrm{Rp} 1.061 .610 .350,02$.

Untuk pendapatan total ini adalah pengurangan penerimaan dengan total biaya baik biaya yang berlaku variabel maupun tetap, sedangkan untuk kontribusi margin merupakan penerimaan dikurangi biaya yang berlaku variabel saja. Adapun berdasarkan tabel di atas hasil perhitungan menunjukan kontribusi margin untuk ikan patin Rp 651.394.400,00 dan ikan lele Rp 602.112.200,00.

\section{Optimalisasi Usaha}

Ada beberapa hal perlu dipertimbangkan agar keuntungan usaha budidaya ikan milik Pak Azmi ini dapat lebih maksimal, yaitu dengan menentukan jumlah kombinasi produk yang mesti diproduksi dengan pemanfaatan sumberdaya sebijaksana mungkin. Untuk memecahkan masalah tersebut perlu dilakukan penelitian mengenai optimalisasi kombinasi kedua jenis ikan yang tepat untuk dibudidayakan.

Dalam pemecahan masalah, terlebih dahulu mengetahui sumber daya apa saja yang dimiliki dan penggunaannya selama proses budidaya ikan. Adapun sumber daya yang dimiliki akan lebih diperjelas pada pembahasan berikut :

\section{Sumber Daya}

Sumber daya dalam budidaya ikan ini adalah semua faktor produksi yang dimiliki suatu usaha untuk melakukan kegiatan produksi barang. Adapun sumberdaya yang dimiliki usaha budidaya ikan milik pak Azmi dapat dilihat pada tabel berikut :

\section{Tabel 5. Rincian Sumberdaya yang Dimiliki}

\begin{tabular}{rlcrrr}
\hline No & Jenis Sumber Daya & Satuan & \multicolumn{2}{c}{ Kebutuhan Sumberdaya } & \multicolumn{2}{c}{$\begin{array}{c}\text { Ketersediaan } \\
\text { Sumberdaya }\end{array}$} \\
\hline 1 & Luas Kolam & $\mathrm{m}^{2}$ & 6.000 & 10.000 & 16.000 \\
2 & Jam Kerja Tenaga Kerja & Jam & 8.526 & 9.966 & 20.034 \\
3 & Modal Kerja & Rp ,- & $1.225 .375 .933,33$ & $1.883 .052 .800,00$ & $3.108 .428 .733,33$ \\
\hline
\end{tabular}

Sumber: Olahan data primer tahun 2015

Berdasarkan penjelasan sebelumnya dapat dirangkum pada tabel di atas. Adapun total sumberdaya yang dimiliki usaha budidaya milik pak Azmi Nur adalah untuk jumlah luasan lahan kolam ikan yang termanfaatkan adalah 16.000 $\mathrm{m}^{2}$, jam kerja dari tenaga kerja adalah 20.034 Jam kerja dan modal kerja berupa uang kas yang dapat sewaktu-waktu digunakan adalah Rp 3.108.428.733,33. 


\section{Lahan Kolam}

Kolam pak Azmi Nur merupakan lahan di pingiran sungai yang digali dengan kedalaman \pm 2 meter, ukuran kolam bervariasi disesuaikan dengan kondisi lahan. Adapun jumlah kolam ikan lele adalah 12 petak dengan luas keseluruhan kolam $6000 \mathrm{~m}^{2}$ dan untuk kolam ikan patin ada 22 petak kolam dengan luas $10000 \mathrm{~m}^{2}$. Dengan keberadaan kolam di tepi sungai Lais, tentu untuk kebutuhan air tidak menjadi kendala. Tetapi yang menjadi kendala di sini adalah luasan kolam itu sendiri. Dengan ketentuan padat tebar ikan yang telah ditentukan oleh pemilik usaha yaitu untuk ikan lele 100 ekor/ $\mathrm{m}^{2}$ dan ikan patin 50 ekor/ $\mathrm{m}^{2}$. Tentu agar memperoleh keuntungan lebih maksimal perlu ditambah luasan areal kolam agar ikan yang dapat dibudidayakan lebih banyak.

Luas lahan kolam ikan sebagai salah satu pembatas untuk analisis linear programming, dimana dengan padat tebar ikan lele 100 ekor/ m² dapat memberikan margin kontribusi sebesar Rp 33.450,68 / Produksi dan untuk ikan patin padat tebar 50 ekor/ $\mathrm{m}^{2}$ memberikan margin kontribusi Rp 32.569,72/ Produksi. Dan untuk cakupan waktu penelitian 10 bulan untuk ikan lele frekuensi produksi 3 kali dan ikan patin 2. Dan dengan luasan kolam ikan total adalah $16000 \mathrm{~m}^{2}$, dalam masa produksi budidaya ikan 10 bulan untuk luasan kolam ikan lele per $\mathrm{m}^{2}$ akan memberikan kontribusi margin sebesar Rp 100.352,04 dan ikan patin per $\mathrm{m}^{2}$ margin kontibusinya $\operatorname{Rp} 65.139,44$. Jadi faktor pembatas/ kendala luas lahan kolam ini dapat dituliskan dengan

$$
X_{1}+X_{2} \leq 16.000
$$

\section{Jam Kerja Tenaga Kerja}

Adapun aktifitas budidaya kedua jenis ikan sama, agar lebih jelas aktifitas budidaya ikan beserta jam kerja yang dibutuhkan dalam proses budidaya ikan dapat dilihat pada tabel berikut: 
Tabel 6. Jam Kerja Tenaga Kerja pada Setiap Aktifitas Budidaya ikan dalam 10 Bulan Produksi

\begin{tabular}{|c|c|c|c|c|c|c|}
\hline \multirow{3}{*}{$\begin{array}{l}\text { Jam Kerja pada } \\
\text { Setiap Aktivitas }\end{array}$} & \multicolumn{6}{|c|}{ Tenaga Kerja (TK) } \\
\hline & \multicolumn{2}{|c|}{$\begin{array}{l}\text { Budidaya Ikan Lele (Jam } \\
\text { TK Tetap } \\
\end{array}$} & \multirow{2}{*}{$\begin{array}{c}\text { Kerja) } \\
\\
\text { TK } \\
\text { Harian }\end{array}$} & \multicolumn{3}{|c|}{ Budidaya Ikan Patin (Jam Kerja) } \\
\hline & $\begin{array}{l}\text { Pembudid } \\
\text { aya Lele }\end{array}$ & $\begin{array}{l}\text { Pembudid } \\
\text { aya Patin) }\end{array}$ & & $\begin{array}{l}\text { Pembudi } \\
\text { daya Lele }\end{array}$ & $\begin{array}{c}\text { Pembudi } \\
\text { daya Patin }\end{array}$ & $\begin{array}{c}\text { TK } \\
\text { Harian }\end{array}$ \\
\hline $\begin{array}{l}\text { Pembersihan dan } \\
\text { Renovasi Kolam }\end{array}$ & 216 & - & 144 & - & 320 & 192 \\
\hline Pemupukan & 180 & - & - & - & 270 & - \\
\hline $\begin{array}{l}\text { Penebaran Benih } \\
\text { Ikan }\end{array}$ & 54 & 90 & & 36 & 60 & - \\
\hline Pemeliharaan Ikan & 1395 & - & - & - & 3110 & - \\
\hline Panen & 432 & 450 & 1440 & 300 & 800 & 1920 \\
\hline Total JK & 2277 & 540 & 1584 & 336 & 4560 & 2112 \\
\hline$\Sigma$ Total JK & \multicolumn{3}{|c|}{4401} & \multicolumn{3}{|c|}{7008} \\
\hline Standar $7 \mathrm{JK} / \mathrm{HOK}$ & \multicolumn{3}{|c|}{ Tenaga Kerja Tetap } & \multicolumn{3}{|c|}{ Tenaga Kerja Harian } \\
\hline 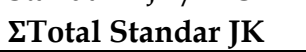 & \multicolumn{3}{|c|}{16800} & \multicolumn{3}{|c|}{3234} \\
\hline
\end{tabular}

Sumber : Olahan data primer tahun 2015

Berdasarkan tabel di atas dapat dilihat bahwa terdapat 2 jenis tenaga kerja, yaitu tenaga kerja tetap dan tenaga kerja harian. Adapun curahan jam kerja untuk budidaya ikan patin dari aktifitas awal hingga akhir secara umum lebih banyak dibandingkan curahan jam kerja untuk budidaya ikan lele. Total jam kerja untuk budidaya ikan patin dalam 10 bulan produksi adalah 7008 jam kerja dan untuk ikan lele 4401 jam. Dengan rincian untuk budidaya ikan patin curahan jam kerja pembudidaya ikan patin itu sendiri 4560 jam kerja, bantuan tenaga kerja pembudidaya ikan lele 336 jam kerja dan tenaga kerja harian 2112 jam kerja. Budidaya ikan lele membutuhkan curahan jam kerja tenaga kerja pembudidaya ikan lele itu sendiri 2277 jam kerja, bantuan tenaga kerja pembudidaya ikan patin 540 dan tenaga kerja harian 1584. Dengan waktu produksi ikan lele yang lebih singkat dibandingkan ikan patin tetapi bantuan jam kerja yang dicurahkan tenaga kerja ikan patin lebih banyak daripada tenaga kerja lele terhadap budidaya ikan patin dikarenakan jumlah tenaga kerja ikan patin lebih banyak yaitu 5 orang dan untuk ikan lele hanya 3 orang.

Dengan standar jam kerja tiap hari 7 jam kerja, maka total standar jam kerja yang dimiliki baik tenaga kerja tetap maupun harian untuk budidaya ikan lele dan patin adalah 20.034 jam kerja. Untuk rumus mencari total sumberdaya jam kerja adalah :

i. Tenaga Kerja Tetap $=$ Standar JK $/$ HOK $\times \Sigma$ TK Tetap $\times \Sigma$ HOK 10 Bulan 
ii. $\quad$ Tenaga Kerja Harian $=$ Standar JK/ HOK $\times \Sigma$ TK Harian $\times \Sigma$ Hari Bekerja dalam 10 Bulan

dimana JK adalah jam Kerja, TK adalah Tenaga Kerja, dan HOK adalah Hari Orang Kerja.

Jam kerja sebagai salah satu pembatas atau faktor kendala untuk perhitungan linear programming, untuk faktor kendala jam kerja ini berapa jam kerja yang dibutuhkan dalam proses budidaya ikan lele maupun patin per $\mathrm{m}^{2}$ dalam 10 bulan produksi dan berapa standar jam kerjanya. Adapun rumusan fungsi kendala jam kerja adalah sebagai beriktu :

$$
0.72 X_{1}+0.70 X_{2} \leq 20034
$$

Rumus untuk mencari nilai koefisien $X_{1}$ atau $X_{2}$ adalah :

koefisienX $_{\mathrm{i}}=\frac{\sum \text { jam kerjaBudidayaikan jenisi dalam } 10 \text { bulan }}{\text { Luas Kolamuntuk jenisikani }}$

\section{Harga Pokok Produksi Variabel (HPP Variabel)}

Harga pokok produksi variabel atau biaya variabel ini merupakan salah satu komponen fungsi kendala untuk analisis linear programming. Fungsi kendala ini dapat dirumuskan dengan mengetahui penggunaan biaya variabel untuk budidaya masing-masing jenis ikan tiap produksi dibagi luas kolam untuk nilai sebelah kiri. Dan nilai sebelah kanan merupakan modal kerja yang tersedia untuk pemenuhan kebutuhan budidaya ikan yang sifatnya variabel. Data untuk perumusan fungsi kendala tersebut telah dirincikan pada pembahasan mengenai biaya variabel. Dan adapun rumusan kendala untuk harga pokok produksi variabel dapat ditulis sebagai berikut :

$$
\text { 204.229,32 } X_{1}+188.305,28 X_{2} \leq 3.108 .428 .733,33
$$

\section{Optimalisasi Kombinasi Ikan}

Dalam penelitian ini, perencanaan optimalisasi kombinasi ikan yang akan dibudidayakan dengan mengalokasikan sumberdaya yang terbatas atau kendala secara optimal akan menggunakan analisis linear programming. Dalam penelitian ini pengolahan data dilakukan menggunakan program POM (Production and Operation Management) For Widows Versi 3.0. Berikut merupakan perumusan persamaan dari masing-masing variable dan fungsi dari linear programming.

\section{Variabel Keputusan:}

$$
\begin{aligned}
& \mathrm{X}_{1}=\text { Ikan Lele }=\text { luasan } \operatorname{kolam}\left(\mathrm{m}^{2}\right) \\
& \mathrm{X}_{2}=\text { Ikan Patin }=\text { luasan } \operatorname{kolam}\left(\mathrm{m}^{2}\right)
\end{aligned}
$$


ISSN -1412-8837

Fungsi tujuan memaksimalkan laba kontribusi marjin (Z):

$$
Z=100.352,04 X_{1}+65.139,44 X_{2}
$$

Fungsi kendala yang menghambat produksi:

i. Luas Kolam :

$$
X_{1}+X_{2} \leq 16000
$$

ii. Jam Kerja Tenaga Kerja :

$$
0.72 X_{1}+0.70 X_{2} \leq 20034
$$

iii. Harga Pokok Produksi Variabel :

$$
\text { 204.229,32 } X_{1}+188.305,28 X_{2} \leq 3.108 .428 .733,33
$$

Setelah dirumuskan nilai-nilai dari fungsi tersebut, pemecahan masalah menentukan kombinasi ikan yang dapat memberikan keuntungan maksimal menggunakan analisis linear programming dapat dilakukan dengan memasukan data ke dalam program POM.

Hasil analisis menunjukkan agar diperoleh kontribusi margin maksimal sebesar Rp 1.527.393.000,-, maka usaha tersebut harus membudidayakan ikan lele pada luasan kolam ikan 15220,29 $\mathrm{m}^{2}$ dan tidak mengusahakan budidaya ikan patin. Dengan padat tebar ikan lele 100 ekor/ $\mathrm{m}^{2}$ maka bibit ikan lele yang dibutuhkan untuk dibudidayakan adalah 1.522.029 ekor bibit ikan lele per produksinya, atau dalam 10 bulan produksi dengan frekuensi budidaya ikan lele 3 kali dibutuhkan 4.566 .087 bibit ikan lele.

Tabel 7. Tingkat Penggunaan Optimal sumberdaya Budidaya Ikan

\begin{tabular}{lllr}
\hline No & \multicolumn{1}{c}{ Variabel } & \multicolumn{1}{c}{ Status } & Tingkat Optimal \\
\hline 1 & Ikan lele $\left(\mathrm{m}^{2}\right)$ & Basic & $15.220,2900$ \\
2 & Ikan Patin (m2) & Non Basic & 0,0000 \\
3 & Slack 1 (Luas kolam) & Basik & 779,7139 \\
4 & Slack 2 (Tenaga kerja) & Basic & $9.075,3940$ \\
5 & Slack 3 (Modal) & Non Basic & 0,0000 \\
6 & Keuntungan (Rp) & & $1.527 .393 .000,0000$ \\
\hline
\end{tabular}

Sumber: hasil analisa POM (2015)

Dari tabel di atas, slack 1 dan slack 2 nilainya secara berturut-turut adalah $779,7139 \mathrm{~m}^{2}$ dan 9075,394 jam kerja. Nilai tersebut mengambarkan bahwa terdapat sumberdaya luas kolam 779,7139 $\mathrm{m}^{2}$ dan 9075,394 jam kerja tenaga kerja yang tidak termanfaatkan dalam proses budidaya ikan milik pak Azmi Nur. Dengan kata lain meskipun dikurangi sumberdaya untuk luas kolam 779,7139 $\mathrm{m}^{2}$ dan 9075,394 jam kerja tenaga kerja itu tidak akan merubah optimasi 
produksi. Dan untuk slack 3 atau modal kerja nilainya 0, dengan demikian untuk modal kerja tidak ada kelebihan atau habis digunakan untuk budidaya ikan.

\section{SIMPULAN DAN SARAN}

\section{Simpulan}

Dari penjelasan yang telah diuraikan sebelumnya maka beberapa hal yang bisa disimpulkan :

1. Pendapatan usaha budidaya ikan milik pak Azmi Nur dalam 10 bulan kegiatan produksi adalah $\mathrm{Rp}$ 1.061.610.350,02. Dengan sumbangsih pendapatan dari produksi ikan lele $\mathrm{Rp} 528.553 .700,00$ dan ikan patin $\mathrm{Rp}$ $533.056 .650,02$.

2. Tingkat optimal kombinasi ikan yang terjadi untuk luasan kolam ikan lele adalah 15.220,29 $\mathrm{m}^{2}$ dan tidak membudidayakan ikan patin, dengan kontribusi marjin maksimal sebesar Rp 1.527.393.000,-. Dan sumberdaya yang berlebih adalah luas kolam seluas $779,7139 \mathrm{~m}^{2}$ dan jam kerja tenaga kerja sebanyak 9075,394 jam.

\section{Saran}

Dari hasil penelitian yang diperoleh disarankan :

1. Agar keuntungan yang diperoleh usaha kolam pak Azmi Nur maksimal, maka usaha tersebut untuk dapat mengkombinasikan ikan lele dengan luasan kolam 15.220,29 m2 dan tidak membudidayakan ikan patin.

2. Agar kegiatan usaha budidaya ikan Pak Azmi Nur lebih optimal, maka sedapat mungkin untuk lebih mengoptimalkan kelebihan sumberdaya luas kolam 779,7139 m2 dan jam kerja tenaga kerja sebesar 9075,394 jam kerja. Pengoptimalan dapat dilakukan dengan meminimalisir pengunaan tenaga kerja ataupun penambahan modal kerja. Dan jika tidak, pengoptimalan kelebihan tenaga kerja untuk lebih difokuskan pada pemeliharaan ikan seperti pergantian air kolam frekuensinya ditingkatkan, dengan kondisi air kolam/ habitat ikan yang selalu baik akan berpengaruh dengan peningkatan produksi ikan, sedangkan luas kolam yang tersisia untuk tetap dibudidayakan ikan, dengan demikian akan memperkecil padat tebar. Padat tebar yang tidak terlalu padat akan mengurangi persaingan ikan dalam memperoleh pakan, sehingga perkembangan ikan merata.

3. Usaha budidaya ikan memiliki prospek untuk dikembangkan, pak Azmi Nur tepat jika memperluas usaha kolam ikan. Dan sedapat mungkin kombinasi ikan dan waktu kegiatan budidaya ditentukan dengan bijak agar keuntungan tetap maksimal dan hasil panen lebih terdistribusi tiap waktunya.

4. Dengan penambahan kolam pak Azmi Nur, diharapkan ada penelitian lanjutan untuk meneliti mengenai kelayakan usaha. 


\section{DAFTAR PUSTAKA}

Laila, Tarwiyatul. 2007. Optimalisasi Kombinasi Produk untuk Memperoleh Laba Maksimal Batik Tulis Aeng Mas Pamekasan dengan Menggunakan Program Linear (Skripsi). Program Studi Pendidikan Matematika, Fakultas Keguruan dan Ilmu Pendidikan, Univeritas Jember, Jember (tidak dipublikas ikan).

Sensus Pertanian Provinsi Bengkulu. 2013. Sensus Pertanian 2013. BPS Provinsi Bengkulu, Bengkulu.

Suhardedi, Cecep. 2010. Strategi Pengembangan Usaha Pembibitan Lele Dumbo (Clarias gariepinus) Di Kabupaten Boyolali. Universitas Sebelas Maret, Surakarta (tidak dipublikas ikan). 